\title{
Effects of Anthropometry Variations on Physiological Parameters of Heart Rate, Oxygen Consumption, Aerobic Power While Performing Manual Operation at Fixed Vice Height
}

\author{
Olusegun Gideon Akanbi ${ }^{*}$, Bukola Olanrewaju Afolabi², Omowumi Adegboye ${ }^{3}$ \\ ${ }^{1}$ Department of Industrial and Production Engineering, University of Ibadan, Ibadan, Nigeria \\ ${ }^{2}$ Department of Agricultural and Bio-Environmental Engineering, Federal College of Agriculture, Ibadan, Nigeria \\ ${ }^{3}$ Department of General Studies, Federal College of Agriculture, Ibadan, Nigeria \\ Email:^engrakanbi@yahoo.com,bukkyblessed@yahoo.co.uk,wumiadgboye@yahoo.com
}

How to cite this paper: Akanbi, O.G., Afolabi, B.O. and Adegboye, O. (2020) Effects of Anthropometry Variations on Physiological Parameters of Heart Rate, Oxygen Consumption, Aerobic Power While Performing Manual Operation at Fixed Vice Height. Engineering, 12, 47-57.

https://doi.org/10.4236/eng.2020.121005

Received: October 8, 2019

Accepted: January 16, 2020

Published: January 19, 2020

Copyright (อ 2020 by author(s) and Scientific Research Publishing Inc. This work is licensed under the Creative Commons Attribution International License (CC BY 4.0).

http://creativecommons.org/licenses/by/4.0/

\begin{abstract}
This study investigated the effect of fixed height standing-workstation on different people with diverse anthropometry dimensions. Measurements of some anthropometric and physiological parameters are carried out as bases for the calculation of body mass index (BMI) and the determination of the maximum heart rate $\left(\mathrm{HR}_{\max }\right)$ and aerobic power $\left(\mathrm{VO}_{2} \max \right)$ of individual subject while performing manual cutting operation with hacksaw on fixed vice height of $940 \mathrm{~mm}$. Twenty subjects (S1 to S20) parted $2 \mathrm{~mm}$ thick square-pipe of $25 \mathrm{~mm} \times 25 \mathrm{~mm}$. Each subject carried out cutting operation in 5 replicates and their physiological parameters during activities are measured to determine their expended energy (EE) and oxygen consumption rate $\left(\mathrm{VO}_{2}\right)$. The results showed that subject $\mathrm{S} 4$ with BMI of $20.76 \mathrm{~kg} / \mathrm{m}^{2}$ has maximum cutting rate of 5.33 stroke/s, while subject $S 8$ with BMI of $23.39 \mathrm{~kg} / \mathrm{m}^{2}$ has minimum cutting rate of 0.92 stroke/s. There was a statistically significant effect on the interaction between BMI, EE and Cutting rate, with $\mathrm{F}=827.54, \mathrm{P}=0.000, \mathrm{R}^{2}$ $=0.967$ and $\mathrm{S}=1.749$ units. Subject $\mathrm{S} 11$ was discovered to have $\mathrm{VO}_{2}(28.54$ $1 / \mathrm{min})$ and $\mathrm{VO}_{2} \max (24.36 \mathrm{ml} / \mathrm{min} / \mathrm{kg})$, with highest value of $\mathrm{EE}(2.94$ $\mathrm{kcal} / \mathrm{min})$. Wear rates of $1.86 \mathrm{teeth} / \mathrm{s}$ and 9.55 teeth/s have the same energy cost $(\mathrm{EE}=0.87 \mathrm{kcal} / \mathrm{min})$ but different cutting time of $36.65 \mathrm{~s}(\mathrm{~S} 18)$ and 10.89 $\mathrm{s}$ (S20) respectively. This could explain in-part that excess $25.76 \mathrm{~s}$ utilized in operation time by subject S18 is responsible for keeping approximately 7.7 teeth intact as regards tool management. EE and Tool Wear Rate in one-way analysis of variance, were statistically significant $\left(F=45.87, P=0.000, R^{2}=\right.$ $54.69 \%$ and $S=1.617$ units) at 0.05 level.
\end{abstract}




\section{Keywords}

Anthropometry Variation, Cutting Operation, Fixed Vice Height, Physiological Parameters, Wear Rate

\section{Introduction}

Presently, technical products, such as some basic hand held tools and many workstations, where daily activities are being carried out are being designed/layout conventionally with a focus primarily on their functional and aesthetic aspects with little or no consideration about end users. This is often true in developing nations, where little or no priority is given to anthropometry variations of the citizens. As observed by [1] "Powered hand tools are the most common hand held industrial products found in many industrial work situations, yet non-powered hand tools such as hammers, screwdrivers, wrenches, hacksaws, pliers, etc. still have its own importance in different industries and daily life situations".

Poor design/layout of manually (hand) operated tools/equipment and their usage for a long time may lead to much energy input with less work actualization, causing early hand fatigue and different hand and arm related musculoskeletal disorder. Several studies have suggested ergonomics criteria for hand tool design relevant in terms of biomechanical and physiological stress [2]. Ergonomic interventions are increasingly used to reduce labour turnover rates, lower costs, increase revenue and accomplish more work with a little work force [3].

Sawing is a process wherein a narrow slit is cut into the workpiece by a tool consisting of a series of narrowly spaced teeth, called a saw blade. Sawing is used to separate work parts into two or more pieces, or to cut off an unwanted section of a part [4]. These processes are often called cut-off operations and since many manufacturing projects require cut-off operations at some point in the production sequence, sawing is an important manufacturing process.

As presented by [4] "basically, sawing is a simple process: As the blade moves past the work, each tooth takes a cut. Depending on the thickness or diameter of the work, the number of teeth cutting at one time varies from two to ten or more. Sawing is one of the most economical means of cutting metal. The saw cut (kerf) is narrow and relatively few chips are produced in making a cut. Therefore, only minimal power is used in removing large amounts of waste metal".

A hacksaw is a fine-tooth saw with a blade under tension in a frame, used for cutting materials such as metal. Hacksawing involves a linear reciprocating motion of the saw against the workpiece. This method of sawing is often used in cut-off operations. Cutting takes place only on the forward stroke of the saw blade. Because of this intermittent cutting action, hacksawing is less efficient than other sawing methods. Hacksawing can be done manually or with a power hacksaw [4]. Handheld hacksaws consist of a metal frame with a handle, and 
pins for attaching a narrow disposable blade. Hacksaw blades are long, thin strips of hardened steel that feature a row of teeth along their cutting edge. Each end of the blade is punched with a small hole that fits onto the saw frame and a screw or other mechanism is used to put the thin blade under tension.

For manual handling operation design, the strength of the joint and muscle is of importance to guide the design of workspace or equipment to reduce work related injuries, and furthermore to help in personnel selection to increase work efficiency [5]. Based on the study conducted by [6] on wrist positions and movements among female operators in a repetitive, non-forceful industrial quality-control work during a physical examination, they concluded that the high prevalence of disorders in the wrists/hands among the operators may resulted from repetitiveness and high speeds.

As reported by [7] that a tool should be adapted to the task rather than having the worker adapt to a general-purpose tool. Care also needs to be taken to include design features so as to reduce the existing limitations in hand tools. It is evident that the use of hand held industrial products can lead to accidents, overexertion, injuries and discomfort when poorly designed or badly used [8].

[9] submitted that, muscular forces are required to perform the physical work, that is, to hold and move the load from one point to another. Muscular activities (muscle contraction and extension) during physical work require energy. Supplying the demanded energy creates loads on the cardiovascular system (heart and blood vessels) and respiratory system. The heart must pump faster to deliver the increased oxygen demand through blood vessels to the involved muscles. [9] and [10] submitted that volume of oxygen intakes $\left(\mathrm{VO}_{2}\right)$ and aerobic power $\left(\mathrm{VO}_{2} \max \right)$ vary significantly among individuals, and are affected by many factors, such as: Somatic factors (body size, age, sex); Psychic factors (attitude, motivation); Environment (altitude, temperature, humidity, etc.); Nature of work (workload or work intensity, duration, rhythm, technique); Physiological characteristics of the individual which are genetically determined (inherited at birth); Posture.

Energy expenditure (EE) is defined as the amount of work done by a body in kilocalories per minute. The EE of a man or woman over a whole day is often divided into different components, which can be individually determined [9].

The relativity of manual hacksawing is paramount among the road side welders, plumbers, as well as in technical workshops in academic and research institutions in Nigeria. Experience has it that, more often, holding device (vices) height is always fixed depending on artisans' preference. However, this study investigates the effect of anthropometry variations on some physiological parameters: heart rate; oxygen consumption; aerobic power; energy expended by the subjects during cutting operation, cutting rate and tool management (wear rate).

\section{Materials and Methods}

The consents of 20 engineering students of Federal College of Agriculture, Moor 
Plantation Ibadan are obtained before the commencement of the measurements and the experiment. The relative anthropometry measurements are carried out by using standard anthropometric measurement techniques. Some physiological parameters, at resting state before the cutting operation and after each cutting operation such as heart rate, body temperature, and blood pressure are measured. Alongside with these, the vice height was measured $(940 \mathrm{~mm})$. The object for experiment is mild steel material of $25 \mathrm{~mm}$ square pipe, having $2 \mathrm{~mm}$ thickness. This is work piece considered for being cut; it was the same across all 5 replicates cut by each subject. The profiles of blades are determined before and after 5 replicate cutting through, so that relative amount of wear can be easily determined.

\subsection{Methods}

In this study, for proper monitoring of needed data, questionnaire was developed for the subjects, age ranged from 16 to 22 years. All relative anthropometry data measured are: stature (overall height), arm length, hand width (thumb included), hand width (thumb excluded), grip length which are measured with metal tape and caliper to the nearest of $0.5 \mathrm{~cm}$, and weight with digital weigh balance of precision screen gauge sensor system, capacity $(150 \mathrm{~kg})$, decision (100 $\mathrm{kg}$ ) LCD (1.0 inches). The wrist type sphygmomanometer (Andon BPM KD-795) was used to measure heart rate and blood pressure, while analogue thermometer (AGARY FEVER CE0197 1/10 ${ }^{\circ} \mathrm{C}$ ), was used to measure body temperature.

The energy expenditure was determined by using [11] formula which is:

$$
\mathrm{EE}=0.039 * \mathrm{HR}-2.33(\mathrm{kcal} / \mathrm{min})
$$

where, $\mathrm{EE}=$ Energy expenditure and $\mathrm{HR}=$ measured heart rate after a task is performed.

The maximum heart rate $\left(\mathrm{HR}_{\max }\right)$ of each subject was determined by using [12] equation:

$$
\mathrm{HR}_{\text {max }}=205.8-0.685 * \operatorname{age}(\mathrm{bpm})
$$

Oxygen consumption rate $\left(\mathrm{VO}_{2}\right)$ is calculated using the relationship presented by [9] [13] and [14], which are:

$$
Y=0.259 X-6.422(\mathrm{~L} / \mathrm{min})
$$

where: $Y=$ predicted oxygen consumption; $X=$ measured heart rate.

Aerobic power $\left(\mathrm{VO}_{2} \max \right)$ was obtained using equation created by a group of researchers to estimate $\mathrm{VO}_{2} \mathrm{max}$ in $\mathrm{ml} / \mathrm{min} / \mathrm{kg}$ as presented by [15]. The equation shows the relationship as follows:

$$
\mathrm{VO}_{2} \max =15 \frac{\mathrm{HR}_{\max }}{\mathrm{HR}_{\text {rest }}}
$$

where $\mathrm{HR}_{\text {rest }}=$ heart rate at rest.

Vice height was measured with metal tape with reference to the workshop floor on which the subjects would stand while cutting. Work piece for each is 
measured out of total length $300 \mathrm{~mm}$ to be separated in $50 \mathrm{~mm}$ in 5 pieces already marked out on the work piece with cutting distance from the vice marked $20 \mathrm{~mm}$. Time taken to cut through as well as cutting strokes were observed and recorded in respect to each replication made by the subjects.

The profiles of saw blades (18 TPI/BD SANDFLEX BI-METAL) was determined by using black paint on the teeth of three (3) randomly selected blades and were dragged on white cardboard to ascertain the relative number of teeth on average peculiar to the blade type and to determine the missing teeth after cutting operation by each subject.

\subsection{Data Analysis}

The collected data from measured anthropometry parameters, calculated heart rates, expended energies and aerobic powers of the subjects was analyzed statistically using Mtb EXE (version 14.1.0.0) and Microsoft Excel (2007) programs. Descriptive statistics were generated for anthropometric variations and were expressed in terms of mean, minimum, maximum, standard deviation, coefficient of variations, skewness, $5^{\text {th }}$ percentile, $50^{\text {th }}$ percentile and $95^{\text {th }}$ percentile. Frequency histograms were generated to compare heart rate at rest and heart rate after the task was performed. Statistical significance, where indicated uses an alpha level of 0.05 . The null hypothesis $\left(\mathrm{H}_{0}\right)$ is presented as follows:

$\mathrm{H}_{0}$ : BMI of individual subject has no significant effect on EE and cutting rate.

$\mathrm{H}_{1}$ : BMI of individual subject has significant effect on EE and cutting rate.

\section{Results and Discussion}

\subsection{Anthropometry Parameters}

The results on descriptive statistics of selected anthropometric measurements of 20 subjects, age ranged 16 to 21 years are presented in Table 1 . The heights of the subjects ranged from $160 \mathrm{~cm}$ to $190 \mathrm{~cm}$, having standard deviation and coefficient of variation of 8.71 and 4.98 respectively.

The values for height, arm reach, leg length and hand grip length are negatively skewed with smallest value of $-84 \%$. This indicates highest level of skewness to the negative side and it is corresponded to the highest value of the coefficient of variations in the group. Whereas, the hand length, hand width with thumb and hand width without thumb are positively skewed, with highest value of $62 \%$. This also corresponded to the highest value of the coefficient of variations in the group. It is noted that the disparity between $50^{\text {th }}$ percentile and mean is most pronounced in leg length compared to the remaining measured parameters, however this is contrary to (whole stature) height. This could justify the fact that height does not necessarily predict the leg length (Table 1).

\subsection{Relationship between Heart Rates before and after Cutting Operations}

Figure 1 showed the effect of activity performed by individual subjects, as 
Table 1. Descriptive statistics for the selected anthropometry parameters.

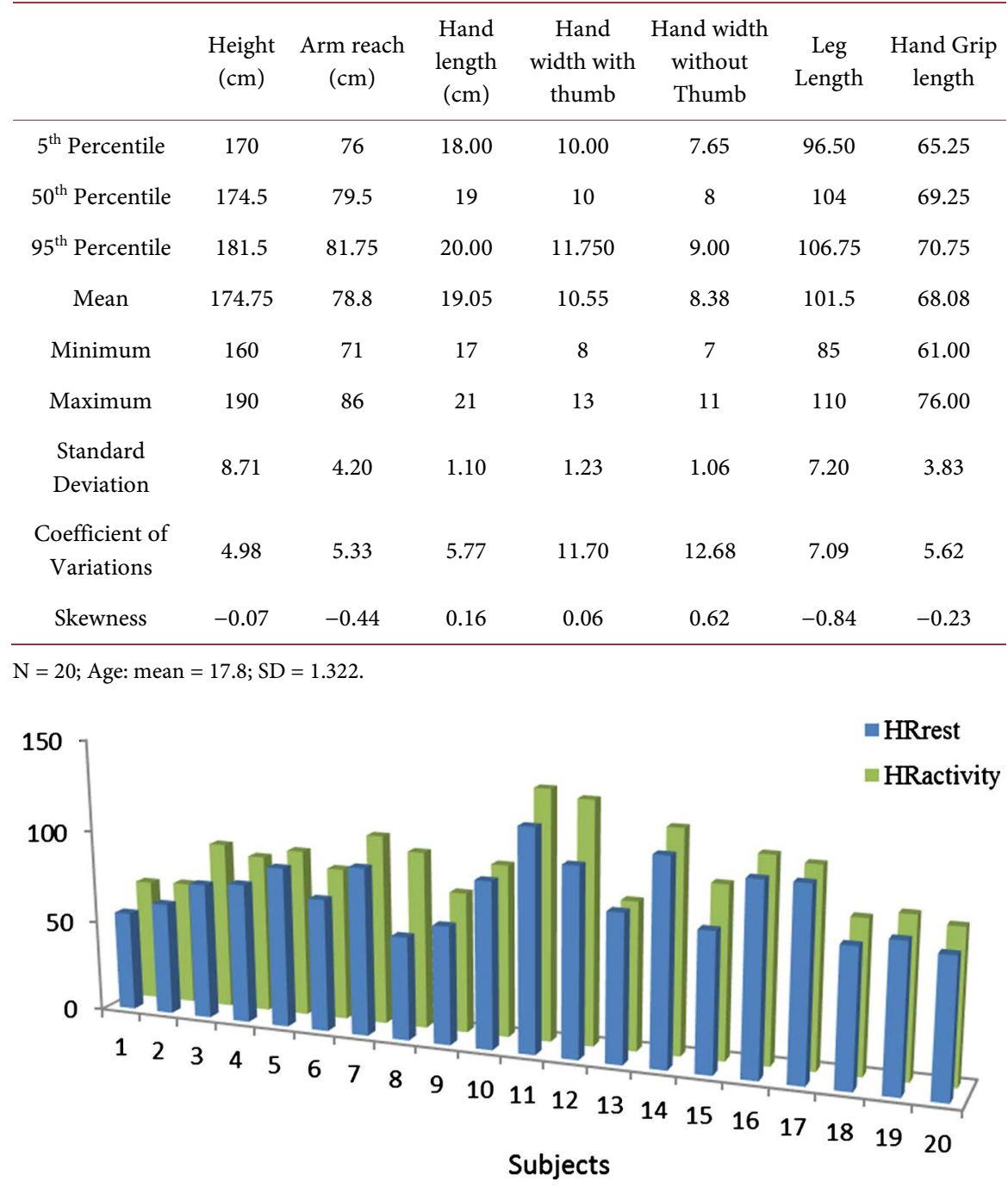

Figure 1. Relationship between heart rate at rest and heart rate after cutting operation.

differences is recorded across all participants in heart rate at rest (HRrest) and heart rate after cutting operation (HRactivity). The histogram bars corresponded to subject 8 , showed major variation in between rest and activity heart rates when compared with the other subjects (Figure 1). From Table 2, it was discovered that subject 8 has the minimum cutting rate of 0.92 stroke/s. This may suggest increment of load for more cutting per unit time.

Subject 11 has the highest value for both HRrest and HRactivity as shown by the representative histogram bars and this is followed by subjects 14 and 12 in HRrest and HRactivity respectively, while subject 1 has the smallest HRrest and HRactivity followed by subjects 8 and 2 in HRrest and HRactivity respectively. Also, subjects 16 and 17 have the same values for HRrest, but disparity of values in HRactivity, with subject 16 having higher value (Figure 1). This is complimented by cutting rate of the duo; subjects $16: 17$ having 2.30 stroke/s:1.03 stroke/s respectively. 


\subsection{Body Mass Index (BMI)}

Table 2, illustrates the relationship of height, body weight and BMI to cutting rate. The maximum cutting rate is 5.33 stroke/s which is correspondent to subject 4 with BMI of $20.76 \mathrm{~kg} / \mathrm{m}^{2}$, while minimum cutting rate is 0.92 stroke/s which is correspondent to subject 8 with BMI of $23.39 \mathrm{~kg} / \mathrm{m}^{2}$. The table also indicated that the greatest value of the BMI was $\left(29.30 \mathrm{~kg} / \mathrm{m}^{2}\right)$ related to cutting rate of 2.58 stroke/s and the smallest value of BMI $\left(15.90 \mathrm{~kg} / \mathrm{m}^{2}\right)$ related to cutting rate of 2.30 stroke/s.

In a one-way ANOVA that was conducted to determine if BMI of the subjects (S1 - S20) has effect on EE and cutting rate exhibited by individual subject in a manual hack-sawing operation. There was a statistically significant effect, with $F$ $=827.54, \mathrm{P}=0.000$ (Table 3 ). The interaction shows strong effect of BMI with EE and Cutting rate, the $\mathrm{R}^{2}$ is 0.967 and $\mathrm{S}$ is 1.749 units.

Table 2. Relative cutting rates (CR) to subjects' body mass indexes (BMI).

\begin{tabular}{|c|c|c|c|c|c|c|}
\hline Subjects & $\begin{array}{c}\text { Body } \\
\text { Weight }(\mathrm{kg})\end{array}$ & $\begin{array}{l}\text { Height } \\
\text { (m) }\end{array}$ & BMI $\left(\mathrm{kg} / \mathrm{m}^{2}\right)$ & $\begin{array}{c}\text { Average } \\
\text { Cutting Time } \\
\text { (s) }\end{array}$ & $\begin{array}{c}\text { Average Stroke } \\
\text { Frequency } \\
\text { (stroke) }\end{array}$ & $\begin{array}{c}\text { Cutting Rate } \\
\text { (stroke/s) }\end{array}$ \\
\hline $\mathrm{S} 1$ & 75 & 1.6 & 29.30 & 17.08 & 44 & 2.58 \\
\hline $\mathrm{S} 2$ & 63 & 1.71 & 21.55 & 17.93 & 33 & 1.84 \\
\hline S3 & 66 & 1.78 & 20.83 & 48.18 & 91 & 1.89 \\
\hline $\mathrm{S} 4$ & 60 & 1.7 & 20.76 & 17.08 & 91 & 5.33 \\
\hline S5 & 61 & 1.76 & 19.69 & 17.28 & 51 & 2.95 \\
\hline S6 & 53 & 1.6 & 20.70 & 24.14 & 43 & 1.78 \\
\hline S7 & 63 & 1.73 & 21.05 & 33.88 & 50 & 1.48 \\
\hline $\mathrm{S} 8$ & 70 & 1.73 & 23.39 & 30.47 & 28 & 0.92 \\
\hline S9 & 65 & 1.7 & 22.49 & 22.68 & 52 & 2.29 \\
\hline $\mathrm{S} 10$ & 74 & 1.8 & 22.84 & 15.87 & 39 & 2.46 \\
\hline $\mathrm{S} 11$ & 64 & 1.7 & 22.15 & 57.59 & 76 & 1.32 \\
\hline $\mathrm{S} 12$ & 62 & 1.61 & 23.92 & 22.23 & 49 & 2.20 \\
\hline $\mathrm{S} 13$ & 79 & 1.88 & 22.35 & 15.73 & 29 & 1.84 \\
\hline $\mathrm{S} 14$ & 64 & 1.76 & 20.66 & 14.33 & 26 & 1.81 \\
\hline S15 & 66 & 1.76 & 21.31 & 24.22 & 43 & 1.78 \\
\hline S16 & 55 & 1.86 & 15.90 & 21.72 & 50 & 2.30 \\
\hline S17 & 66 & 1.82 & 19.93 & 13.6 & 14 & 1.03 \\
\hline S18 & 69 & 1.9 & 19.11 & 36.65 & 53 & 1.45 \\
\hline S19 & 58 & 1.84 & 17.13 & 19.43 & 27 & 1.39 \\
\hline S20 & 53 & 1.71 & 18.13 & 10.89 & 21 & 1.93 \\
\hline Mean & 64.3 & 1.75 & 21.16 & 24.049 & 45.5 & 2.03 \\
\hline Max & 79 & 1.9 & 29.30 & 57.59 & 91 & 5.33 \\
\hline Min & 53 & 1.6 & 15.90 & 10.89 & 14 & 0.92 \\
\hline $\mathrm{SD}$ & 6.914 & 0.087 & 2.787 & 11.985 & 20.974 & 0.931 \\
\hline
\end{tabular}




\subsection{Estimated Physiological Parameters and Their Relationship to Some Operational Parameters}

Table 4, presents estimation of maximum heart rate $\left(\mathrm{HR}_{\max }\right)$, aerobic power

Table 3. One-way ANOVA for BMI, EE, C.RATE.

\begin{tabular}{cccccc}
\hline Source & DF & SS & MS & F & P \\
\hline Factor & 2 & 5063.78 & 2531.89 & 827.54 & 0.000 \\
Error & 57 & 174.39 & 3.06 & & \\
Total & 59 & 5238.17 & & & \\
\hline
\end{tabular}

$S=1.749 ; R^{2}=96.67 \% ; R^{2}(\operatorname{adj})=96.55 \%$.

Table 4. Estimation of Maximum Heart Rate $\left(\mathrm{HR}_{\max }\right)$, Aerobic Power $\left(\mathrm{VO}_{2} \mathrm{max}\right)$, Oxygen Consumption Rate $\left(\mathrm{VO}_{2}\right)$ and Energy Expenditure (EE) with respect to Cutting Time and Tool Wear Rate.

\begin{tabular}{|c|c|c|c|c|c|c|c|c|}
\hline Subjects & $\mathrm{HR}_{\max }$ & $\begin{array}{c}\mathrm{VO}_{2} \mathrm{max} \\
(\mathrm{ml} / \mathrm{min} / \mathrm{kg})\end{array}$ & $\mathrm{VO}_{2}$ & $\begin{array}{c}\mathrm{EE} \\
(\mathrm{kcal} / \mathrm{min})\end{array}$ & $\begin{array}{l}\text { Average } \\
\text { Cutting } \\
\text { Time (s) }\end{array}$ & $\begin{array}{c}\text { Number of } \\
\text { Removed } \\
\text { Teeth }\end{array}$ & $\begin{array}{l}\% \text { Tool } \\
\text { Wear }\end{array}$ & $\begin{array}{c}\text { Tool Wear } \\
\text { Rate } \\
\text { (teeth/s) }\end{array}$ \\
\hline S1 & 192.785 & 53.55 & 10.67 & 0.24 & 17.08 & 70 & 35 & 4.1 \\
\hline S2 & 193.47 & 47.57 & 10.93 & 0.28 & 17.93 & 120 & 60 & 6.69 \\
\hline S3 & 193.47 & 39.22 & 17.15 & 1.22 & 48.18 & 140 & 70 & 2.91 \\
\hline S4 & 194.155 & 38.32 & 15.85 & 1.02 & 17.08 & 94 & 47 & 5.5 \\
\hline S5 & 194.155 & 33.48 & 17.15 & 1.22 & 17.28 & 108 & 54 & 6.25 \\
\hline S6 & 194.84 & 40.59 & 15.08 & 0.91 & 24.14 & 79 & 39.5 & 3.27 \\
\hline S7 & 193.47 & 31.89 & 20.26 & 1.69 & 33.88 & 151 & 75.5 & 4.46 \\
\hline S8 & 192.1 & 51.46 & 18.44 & 1.41 & 30.47 & 112 & 56 & 3.68 \\
\hline S9 & 193.47 & 45.34 & 13.26 & 0.63 & 22.68 & 153 & 76.5 & 6.75 \\
\hline S10 & 194.155 & 32.36 & 17.67 & 1.30 & 15.87 & 82 & 41 & 5.17 \\
\hline S11 & 194.84 & 24.36 & 28.54 & 2.94 & 57.59 & 164 & 82 & 2.85 \\
\hline $\mathrm{S} 12$ & 193.47 & 28.45 & 27.50 & 2.78 & 22.23 & 90 & 45 & 4.05 \\
\hline S13 & 191.415 & 35.89 & 14.29 & 0.79 & 15.73 & 111 & 55.5 & 7.06 \\
\hline S14 & 194.155 & 26.24 & 24.65 & 2.35 & 14.33 & 29 & 14.5 & 2.02 \\
\hline S15 & 194.155 & 38.83 & 17.66 & 1.30 & 24.22 & 91 & 45.5 & 3.76 \\
\hline S16 & 194.84 & 28.37 & 22.06 & 1.96 & 21.72 & 47 & 23.5 & 2.16 \\
\hline S17 & 193.47 & 28.18 & 21.29 & 1.84 & 13.6 & 117 & 58.5 & 8.6 \\
\hline S18 & 192.785 & 39.08 & 14.81 & 0.87 & 36.65 & 68 & 34 & 1.86 \\
\hline S19 & 192.785 & 36.60 & 15.85 & 1.02 & 19.43 & 101 & 50.5 & 5.2 \\
\hline $\mathrm{S} 20$ & 194.155 & 39.36 & 14.82 & 0.87 & 10.89 & 104 & 52 & 9.55 \\
\hline Mean & 193.61 & 36.96 & 17.90 & 1.33 & 24.049 & 101.55 & 50.78 & 4.79 \\
\hline Max & 194.84 & 53.55 & 28.54 & 2.94 & 57.59 & 164 & 82 & 9.55 \\
\hline Min & 191.42 & 24.36 & 10.67 & 0.24 & 10.89 & 29 & 14.5 & 1.86 \\
\hline SD & 0.91 & 8.14 & 4.91 & 0.74 & 11.985 & 34.68 & 17.34 & 2.16 \\
\hline
\end{tabular}

Vice Height $=0.94 \mathrm{~m}$; Total number of teeth per Hack saw Blade $=200$. 
$\left(\mathrm{VO}_{2} \max \right)$, oxygen consumption rate $\left(\mathrm{VO}_{2}\right)$ and energy expenditure (EE) with respect to cutting time and tool wear rate. In this analysis, the direct relationship among the variables was ascertained.

The variations in $\mathrm{VO}_{2} \max$ for all subjects were from $24.36 \mathrm{ml} / \mathrm{min} / \mathrm{kg}$ to 53.55 $\mathrm{ml} / \mathrm{min} / \mathrm{kg}$, while EE varied from $0.24 \mathrm{kcal} / \mathrm{min}$ to $2.94 \mathrm{kcal} / \mathrm{min}$. The mean \pm $\mathrm{SD}$ for $\mathrm{HR}_{\max }$ and $\mathrm{VO}_{2}$ were $193.61 \mathrm{bpm} \pm 0.91$ and $17.90 \mathrm{l} / \mathrm{min} \pm 4.91 \mathrm{respec}-$ tively.

As presented in Figure 2, also in Table 5, minimum wear rate of 1.86 teeth/s, with overall wear percentage of 34\% corresponded to subject S18 with EE of 0.87 $\mathrm{kcal} / \mathrm{min}$ and $36.65 \mathrm{~s}$ cutting time on average. It was noted that subject 20 also expended equivalent energy of $0.87 \mathrm{kcal} / \mathrm{min}$ within lesser average cutting time of $10.89 \mathrm{~s}$ and 9.55 teeth/s wear rate (52\%). This could be estimated in-part that $42.9 \%$ gained in operation time by subject S20 is amounted to $18 \%$ loss due to tool management. Consequently, subjects S3 and S5 also expended the same energy $(1.22 \mathrm{kcal} / \mathrm{min})$, but wear rates of $2.91 \mathrm{teeth} / \mathrm{s}$ and 6.25 teeth $/ \mathrm{s}$ respectively corresponded to average cutting times of $48.18 \mathrm{~s}$ and $17.28 \mathrm{~s}$. This could imply the relatively higher wear rate by subject $\mathrm{S} 5$ may be due to a decrease in cutting time. This follows the same trend as subjects S18 and S20 (Figure 2 and Table 4).

The relationship between EE and Tool Wear Rate in one-way analysis of variance, was statistically significant $\mathrm{F}=45.87, \mathrm{P}=0.000$ at 0.05 level (Table 5). The $\mathrm{R}^{2}$ and $\mathrm{S}$ indicate that, the EE explains $54.69 \%$ of the variation in the Tool Wear Rate and the remaining $45.31 \%$ is not explained which means that the rest

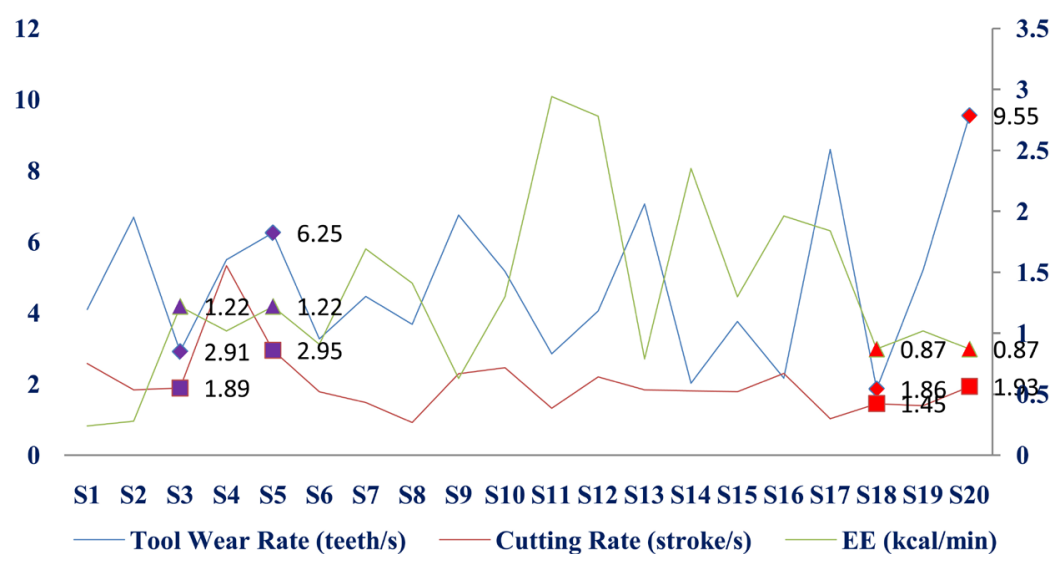

Figure 2. Relationship of physiological parameter, operational parameter and tool management.

Table 5. One-way ANOVA for EE and tool wear rate.

\begin{tabular}{cccccc}
\hline Source & DF & SS & MS & F & P \\
\hline Factor & 1 & 119.88 & 119.88 & 45.87 & 0.000 \\
Error & 38 & 99.32 & 2.61 & & \\
Total & 39 & 219.20 & & & \\
\hline
\end{tabular}

$S=1.617 ; R^{2}=54.69 \% ; R^{2}($ adj $)=53.50 \%$. 
$45.31 \%$ of the variation of EE is related to other variables which are not captured, while the standard deviation between the data points and the fitted values is approximately 1.617 units.

\section{Conclusions}

Generally from the anthropometric analysis results coefficient of variations of the measured parameters indicated normally distributed data $(<10)$ except for hand-width with and without thumb. Leg length has highest level of skewness to the negative side with value of $-84 \%$ and the hand-width without thumb is positively skewed, with highest value of $62 \%$.

From the study conducted the results evidently assert that $\mathrm{BMI}, \mathrm{VO}_{2}$ and $\mathrm{EE}$ have effects on cutting time, cutting rate and tool wear rate.

Body Mass Indexes (BMI) showed significant effects on interactions with EE, cutting rate, and wear rate at $\alpha=5 \%$. Based on stated hypothesis, null hypothesis was rejected.

It is evident that anthropometry variations have effects on physiological responses of individual subjects as well as tool management with $\mathrm{F}=827.54, \mathrm{P}=$ 0.000 and the $\mathrm{R}^{2}$ value of 0.967 .

The proper matching of machine requirements with the human capabilities is basically necessary for optimum performance, it was observed that subjects S3 and S5 expended the same energy of $1.22 \mathrm{kcal} / \mathrm{min}$, but different wear rates: cutting time of 2.91 teeth/s:48.18 s and 6.25 teeth/s:17.28s respectively. It could be deduced from this that the increase in wear rates of the tool is relatively corresponding to decrease in cutting time by the subjects, as the same is applicable to subjects S18 and S20.

The main contribution from this investigative study is that it serves as eye opener into hazardous effect of fixed-vice height on manual hack-sawing users, which may be unnoticed by many. Areas of biomechanics are more needful area of attention for comprehensive information, as the scope of the work did not address the area.

\section{Acknowledgements}

The workshop staff at the metal works and fabrication section in the Department of Agricultural and Bio-Environmental Engineering of the Federal College Agriculture, Ibadan and every individual that makes themselves available as subject for the success of this research work are well appreciated.

\section{Conflicts of Interest}

The authors declare no conflicts of interest regarding the publication of this paper.

\section{References}

[1] Kong, Y.K., Lowe, B.D., Lee, S.J. and Krieg, E.F. (2008) Evaluation of Handle Shapes 
for Screwdriving. Applied Ergonomics, 39, 191-198. https://doi.org/10.1016/j.apergo.2007.05.003

[2] Byungjoon, B.J.K. (2012) Effect of Ergonomic Design Changes in Hand Tools on Physiological Cost and Subjective Ratings. International Journal of Occupational Safety and Ergonomics, 18, 267-277. https://doi.org/10.1080/10803548.2012.11076932

[3] Vyavahare, R.T. and Kallurkar, S.P. (2012) Anthropometric and Strength Data of Indian Agricultural Workers for Equipment Design: A Review. Agricultural Engineering International: CIGR Journal, 14, 102-114. http://www.cigrjournal.org

[4] George, S. (2010) Cutting Tool Applications: Saws \& Sawing. American Machinist, Machining/Cutting.

[5] Liang, M., Wei, Z., Damien, C., Fouad, B., François, G.M.L., Zhang, W., Bennis, F., Chablat, D. and Guillaume, F. (2009) Multi-Objective Optimisation Method for Posture Prediction and Analysis with Consideration of Fatigue Effect and Its Application Case. Computers \& Industrial Engineering, 57, 1235-1246. https://doi.org/10.1016/j.cie.2009.06.003

[6] Arvidsson, I., Akesson, I. and Hansson, G.A. (2003) Wrist Movements among Females in a Repetitive, Non-Forceful Work. Applied Ergonomics, 34, 309-316. https://doi.org/10.1016/S0003-6870(03)00042-5

[7] Bisht, D.S. and Khan, M.R. (2013) Ergonomic Assessment Methods for the Evaluation of Hand Held Industrial Products: A Review. Proceedings of the World Congress on Engineering, London, 3-5 July 2013, Vol. 1.

[8] Aghazadeh, F. and Mital, A. (1987) Injuries Due to Hand Tools. Applied Ergonomics, 18, 273-278. https://doi.org/10.1016/0003-6870(87)90134-7

[9] Afolabi, B.O., Adejumo, A.O.D. and Jokanola, O.O. (2015) Comparative Assessment of Two Methods in the Production of Fermented Cassava Flour (Láfún) on Manual Energy Expended Retting Time and the Product Quality. Food Science and Quality Management, 42, 20-28.

[10] Tayyari, F. and Smith, J. (2003) Occupational Ergonomics Principles and Applications. Kluwer Academic Publishers, Boston.

[11] Varghese, M.A., Saha, P.N. and Atreya, N. (1994) A Rapid Appraisal of Occupational Workload from a Modified Scale of Perceived Exertion. Ergonomics, 37, 485-491. https://doi.org/10.1080/00140139408963665

[12] Robergs, R.A. and Landwehr, R. (2002) The Surprising History of the " $\mathrm{Hr}_{\max }=220$ - Age" Equation. Journal of Exercise Physiology Online, 5, 1-10.

[13] Scott, P.A. and Charteris, J. (2004) In Cultural Ergonomics. Chap. 8, Elsevier, Oxford, 228, 242.

[14] Afolabi, B.O., Adejumo, A.O.D. and Adegbulugbe, T.A. (2013) Ergonomics Effects on Output Capacities of Two Selected Locally Fabricated Engine Powered Maize Shellers. International Journal of Advances in Science and Technology, 6, 99-118.

[15] Afolabi, B.O. and Akanbi, O.G. (2013) Effects of Body Mass Index on Aerobic Power $\left(\mathrm{VO}_{2} \mathrm{Max}\right)$ and Energy Expenditure (EE): Case of Manual Load Lifting in Agro-Processing. International Journal of Scientific and Engineering Research, 4, 1718-1721. 